\title{
A feast of reviews about brain and pituitary tumor pathology
}

\author{
David N. Louis ${ }^{1}$
}

Published online: 17 April 2018

(c) The Japan Society of Brain Tumor Pathology 2018

Oliver Wendell Holmes, Sr. (1809-1894) was a physician and writer. As a physician, he was a faculty member at Harvard Medical School and he worked at the Massachusetts General Hospital [1]. His work took him abroad, and he trained in the 1830s with the physician and pathologist, Pierre Charles Alexandre Louis (1787-1872) [2]—who was, alas, no family relation to the present writer. As a doctor, Holmes is remembered for his pioneering work on puerperal fever and for his introducing the microscope to Harvard Medical School. As a writer, he was known for his insightful and often humorous essays, most famously for his Breakfast-Table series. Notably, these collections of essays involve the author talking over breakfast with others about a wide range of topics. In this context, Holmes understood that ideas are often best communicated with food and drink. (Indeed, the word "symposium" derives from the Greek "to drink together".) And Holmes himself claimed that "the true essentials of a feast are only fun and feed".

Like Holmes, I have spent my career using microscopes at Massachusetts General Hospital and Harvard Medical School. My work has also taken me to a variety of places in the world, including three wonderful trips to Japan, and among the most memorable aspects of my visits to Japan, the food has been a highlight. The care with which Japanese meals are prepared and served is spectacular, with each meal being a feast in one way or another. So it is with this symposium: a carefully prepared feast of review articles, all relating to either the 2016 update of the World Health Organization Classification of Tumors of the Central Nervous System or the pituitary gland chapters in the 2017 update of the World Health Organization Classification of Tumors of Endocrine Organs.

The "appetizers" are nice overviews of key aspects of pituitary tumor pathology, with an emphasis on changes

David N. Louis

dlouis@mgh.harvard.edu

1 Massachusetts General Hospital and Harvard Medical School, Boston, USA brought about in the 2017 update. Nishioka et al. and Inoshito et al. focus on anterior pituitary tumor pathology, including the use of transcription factor immunohistochemistry for classification and the criteria to define more aggressive tumors. Shibuya, on the other hand, reviews developments specifically relating to the tumors of the posterior pituitary gland.

The "main course entrees" feature studies looking at the combined histological-genetic classification of diffuse gliomas. Iuchi et al. evaluate the 2016 and 2007 World Health Organization Classifications of Tumors of the Central Nervous System in a large series of patients treated in a single institution, confirming the value of the 2016 system. Akagi et al. use the 2016 classification in a similarly large series, finding that the classification works well but that there may be challenges with the molecular technologies. In addition, Yamamichi et al. study the role of ATRX immunohistochemistry to determine if it is an accurate surrogate for molecular genetic evaluation of the ATRX gene, also drawing attention to some of the challenges in using this approach.

The "desserts" leave us with some tastes for the future. Kanamori et al. address the possibility of using liquid chromatography/electrospray ionization tandem mass spectrometry to detect 2-hydroxyglutarate and thus infer IDH mutation status rapidly at the time of frozen section diagnosis. In addition, Ohno et al. explore the relationships between neuroimaging findings and genetic features-so-called radiogenomics. The future will no doubt witness many such technological advances in moving the field of brain tumor classification forward.

I congratulate the editors of this useful collection of reviews as well as the authors of the individual pieces. For those of us interested in brain and pituitary tumor pathology, to paraphrase Holmes, the following symposium is a fun and nutritious feast. 


\section{References}

1. Louis DN, Young RH (2011) The early years (1811-1896). In: Louis DN, Young RH (eds) Keen minds to explore the dark continents of disease: a history of the pathology services at the Massachusetts General Hospital. MGH, Boston

2. McCullough D (2011) The medicals. In: The greater journey: Americans in Paris. Simon \& Schuster, New York 